\title{
Effect of spontaneous breathing on ventilator- induced lung injury in mechanically ventilated healthy rabbits: a randomized, controlled, experimental study
}

\author{
Jingen Xia, Bing Sun, Hangyong He, Heng Zhang, Chunting Wang and Qingyuan Zhan*
}

\begin{abstract}
Introduction: Ventilator-induced lung injury (VILI), one of the most serious complications of mechanical ventilation (MV), can impact patients' clinical prognoses. Compared to control ventilation, preserving spontaneous breathing can improve many physiological features in ventilated patients, such as gas distribution, cardiac performance, and ventilation-perfusion matching. However, the effect of spontaneous breathing on VILI is unknown. The goal of this study was to compare the effects of spontaneous breathing and control ventilation on lung injury in mechanicallyventilated healthy rabbits.
\end{abstract}

Methods: Sixteen healthy New Zealand white rabbits were randomly placed into a spontaneous breathing group (SB Group) and a control ventilation group (CV Group). Both groups were ventilated for eight hours using biphasic positive airway pressure (BIPAP) with similar ventilator parameters: inspiration pressure $\left(\mathrm{P}_{1}\right)$ resulting in a tidal volume (VT) of 10 to $15 \mathrm{ml} / \mathrm{kg}$, inspiratory-to-expiratory ratio of 1:1, positive end-expiration pressure (PEEP) of 2 $\mathrm{CmH}_{2} \mathrm{O}$, and $\mathrm{FiO}_{2}$ of 0.5 . Inflammatory markers in blood serum, lung homogenates and bronchoalveolar lavage fluid (BALF), total protein levels in BALF, mRNA expressions of selected cytokines in lung tissue, and lung injury histopathology scores were determined.

Results: Animals remained hemodynamically stable throughout the entire experiment. After eight hours of MV compared to the CV Group, the SB Group had lower $\mathrm{PaCO}_{2}$ values and ratios of dead space to tidal volume, and higher lung compliance. The levels of cytokines in blood serum and BALF in both groups were similar, but spontaneous breathing led to significantly lower cytokine mRNA expressions in lung tissues and lower lung injury histological scores.

Conclusions: Preserving spontaneous breathing can not only improve ventilatory function, but can also attenuate selected markers of VILI in the mechanically-ventilated healthy lung.

\section{Introduction}

Ventilator-induced lung injury (VILI) is one of the most serious complications of mechanical ventilation (MV). The main mechanisms involved are over-distension of alveoli at high lung volume (volutrauma) and cyclic opening and closing of peripheral airways at low lung volume (atelectotrauma) [1]. VILI can result in serious

\footnotetext{
* Correspondence: dr.zhanqy@gmail.com

Department of Respiratory and Critical Care Medicine, Beijing Institute of Respiratory Medicine, Beijing Chao-Yang Hospital, Capital Medical University, 8 Gongren Tiyuchang South Road, Beijing, 100020, PR China
}

lung parenchymal insults, such as increased permeability of the alveolar-capillary barrier, pulmonary edema, atelectasis, and parenchymal damage [2]. It may also result in the development of inflammatory responses in the local pulmonary and systemic circulations (biotrauma) $[3,4]$, which can then affect the functions of other organs [5,6]. It is commonly accepted that increased production of cytokines, particularly interleukin (IL)-6, IL-1 $\beta$, IL-10, tumor necrosis factor (TNF)- $\alpha$, and macrophage inflammatory protein (MIP)-2, plays a key role in initiating or perpetuating lung injury [3-7]. 
Many clinical studies show that a "lung protective ventilation strategy", which decreases the induction of these cytokines, can remarkably improve patients' clinical outcomes [8-10].

Preserving spontaneous breathing is associated with fewer complications than control ventilation during positive pressure respiratory support, such as by increasing the gas distribution of dependent lung regions [11-14], improving cardiac performance [14-16], promoting ventilation-perfusion matching $[14,15,17]$, preventing diaphragm disuse atrophy $[18,19]$, and decreasing the use of sedative and analgesic drugs [16]. However, the effect of spontaneous breathing on VILI is unknown. Activation of the inspiratory muscles, particularly the diaphragm, can induce greater negative pleural pressures and transalveolar pressures, which can improve the homogenous distribution of ventilation [14], diminish atelectasis $[12,20]$, and thereby reduce lung mechanical stress and strain. However, spontaneous breathing during MV may subsequently induce some conditions that can aggravate lung injury, such as alveolar over-distension caused by increased transalveolar pressure [21], higher pulmonary capillary blood flow caused by increased cardiac output [22], a rapid respiratory rate [23], patient-ventilator asynchrony [24] and others. Recently, several experimental studies showed that preserving spontaneous breathing during mechanical ventilation can attenuate VILI in lung with acute lung injury (ALI) [25-27].

We hypothesized that spontaneous breathing during $\mathrm{MV}$, as compared to control ventilation, would attenuate changes in selected markers of VILI in the healthy lung. To test this hypothesis, we used a rabbit model of the normal lung. Lung injury was evaluated by the levels of inflammatory markers in blood serum and bronchoalveolar lavage fluid (BALF), mRNA expressions of selected cytokines in lung tissues, and lung histopathology examinations.

\section{Materials and methods}

The study was conducted with the approval of the Animal Care Committee of Capital Medical University (Beijing, China), and all animal procedures were carried out in compliance with Institutional Standards for the Care and Use of Laboratory Animals.

\section{Animals and anesthesia}

Our experiments were performed with 24 healthy New Zealand white rabbits, with weights ranging from 2.0 to $2.6 \mathrm{~kg}$. Animals were anesthetized with $3 \%$ pentobarbital sodium (Sigma Chemical Co., St. Louis, MO, USA) at $25 \mathrm{mg} / \mathrm{kg}$ followed by continuous infusion of $3 \%$ pentobarbital sodium at 1 to $2 \mathrm{mg} / \mathrm{kg} / \mathrm{h}$. Then, an endotracheal tube (inner diameter of $4 \mathrm{~mm}$ ) was inserted via tracheotomy. Rabbits were mechanically ventilated
(Evita 4, Drager Medical AG \& Co., KGaA, Lübeck,Germany) using the biphasic positive airway pressure (BIPAP) mode with baseline ventilator settings: $\mathrm{FiO}_{2}$ of 0.5 ; positive end-expiration pressure (PEEP) of 2 $\mathrm{cmH}_{2} \mathrm{O}$; inspiration pressure $\left(\mathrm{P}_{\mathrm{I}}\right)$ resulting in a tidal volume (VT) of 10 to $15 \mathrm{ml} / \mathrm{kg}$; respiratory rate (RR) of 30 breaths/minute; and inspiratory-to-expiratory (I:E) ratio of $1: 1$. If necessary, $\mathrm{RR}$ was adjusted to maintain $\mathrm{PaCO}_{2}$ within 35 to $60 \mathrm{mmHg}$. If $\mathrm{PaCO}_{2}$ was not within this range when $\mathrm{RR}$ was 50 breaths/minute, we increased $\mathrm{P}_{\mathrm{I}}$ by 1 to $2 \mathrm{cmH}_{2} \mathrm{O}$ each time. $\mathrm{FiO}_{2}$ and inspiratory-to-expiratory ratio were not changed during the entire experiment. If spontaneous breathing occurred, which was assessed by capnography [28], Pipecuronium Bromide (Gedeon Richter Plc. Budapest, Hungary) at $0.3 \mathrm{mg} / \mathrm{kg} / \mathrm{h}$ was infused for muscle relaxation.

One 20-gauge catheter was placed in a marginal ear vein for fluid and drug administration. A second catheter was inserted into a carotid artery to monitor blood pressure (BP) and heart rate (HR) and for blood gas sampling. A third catheter was placed in a jugular vein to monitor central venous pressure and for sampling venous blood.

\section{Experimental protocol}

After surgical intervention was completed, BP and HR readings that fluctuated by less than $20 \%$ were used as baseline. Non-ventilated animals (control animals; $n=$ 8) were immediately sampled after sedation and tracheostomized to avoid hypercapnia. The other sixteen rabbits were randomly sorted (opaque sealed envelopes) into a control ventilation group (CV Group; $n=8$ ) and a spontaneous breathing group (SB Group; $n=8$ ) (Figure 1). Normal saline $(0.9 \%)$ was administered as a maintenance fluid at the rate of 8 to $10 \mathrm{ml} / \mathrm{kg} / \mathrm{h}$. If mean arterial blood pressure was lower than $80 \mathrm{mmHg}$, fluid boluses of $5 \mathrm{ml} / \mathrm{kg}$ of normal saline were administrated. All animals received similar amounts of total IV fluids over eight hours.

After eight hours of MV, all animals were exsanguinated via a carotid artery, and lung tissues and heart were harvested. Bronchoalveolar lavage (BAL) was performed for the left lower lobes. Tissue samples from the left upper lobes were stored in liquid nitrogen for selected cytokine mRNA analyses. Tissue samples of the right four lobes of all animals were immediately fixed in $10 \%$ buffered formalin for histological analysis.

\section{Ventilator setting}

For the CV Group, the animals' SB was inhibited continuously and all animals were ventilated with the same baseline ventilator parameters during the entire experiment. For the SB Group, to regain a rabbit's spontaneous breathing, muscle relaxant infusion was stopped 


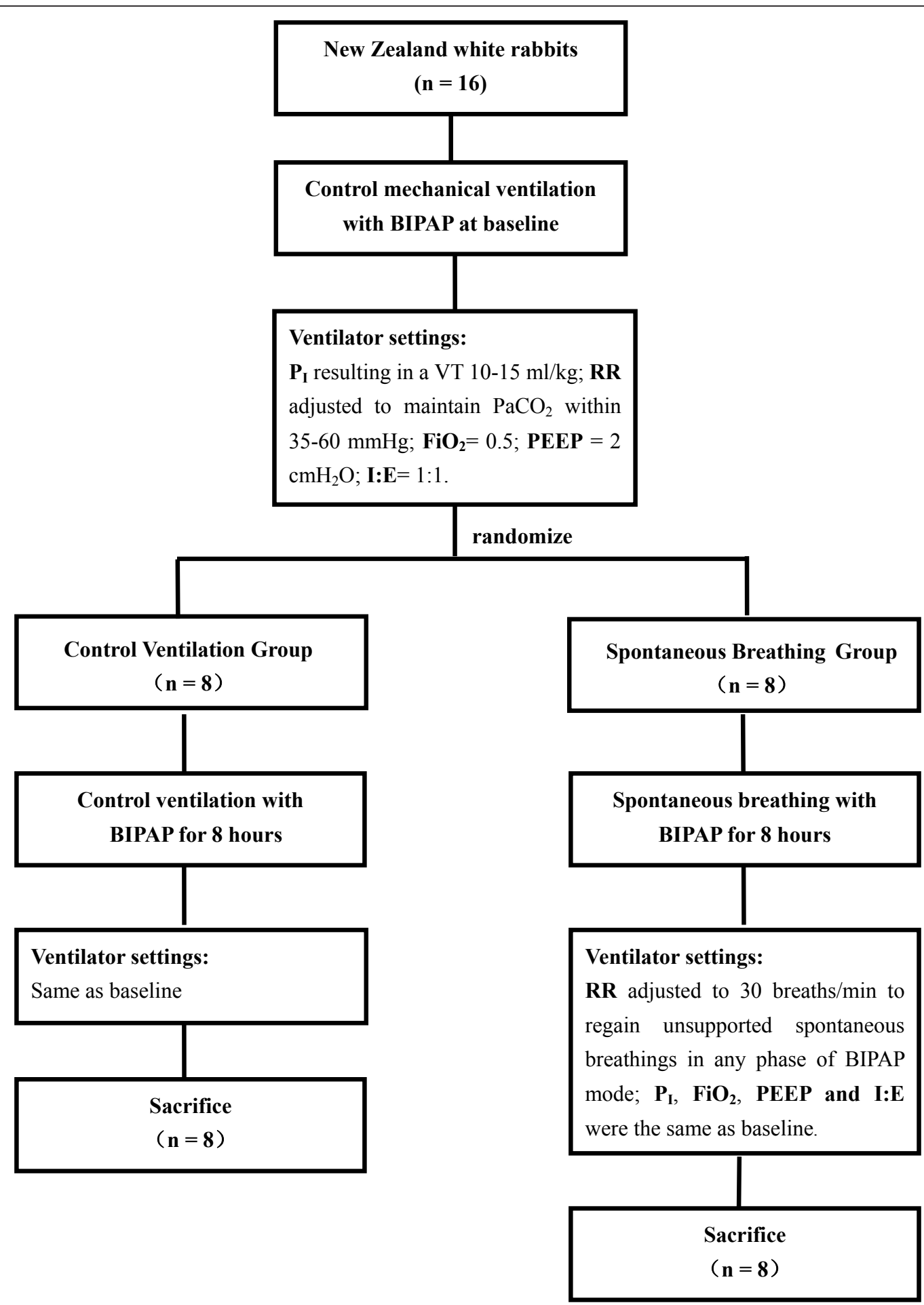

Figure 1 Flow chart of experiment. BIPAP, biphasic positive airway pressure; $\mathrm{FiO}_{2}$, fraction of inspired oxygen; I:E, inspiratory-to-expiratory ratio; PEEP, positive end-expiration pressure; $\mathrm{P}_{1}$, inspiratory pressure; $R R$, respiratory rate; $V T$, tidal volume.

and the pentobarbital sodium infusion rate was lowered; then ventilator $R R$ was decreased to 30 breaths/minute to make sure that rabbits could show unsupported spontaneous breathings at high pressure $\left(\mathrm{P}_{\mathrm{I}}\right)$ and low pressure (PEEP) levels of BIPAP mode; and the other parameters were not different from baseline ventilator settings, including $\mathrm{P}_{\mathrm{I}}$, PEEP, I:E ratio and $\mathrm{FiO}_{2}$ (Figure 2 ); the dose of pentobarbital sodium was carefully 

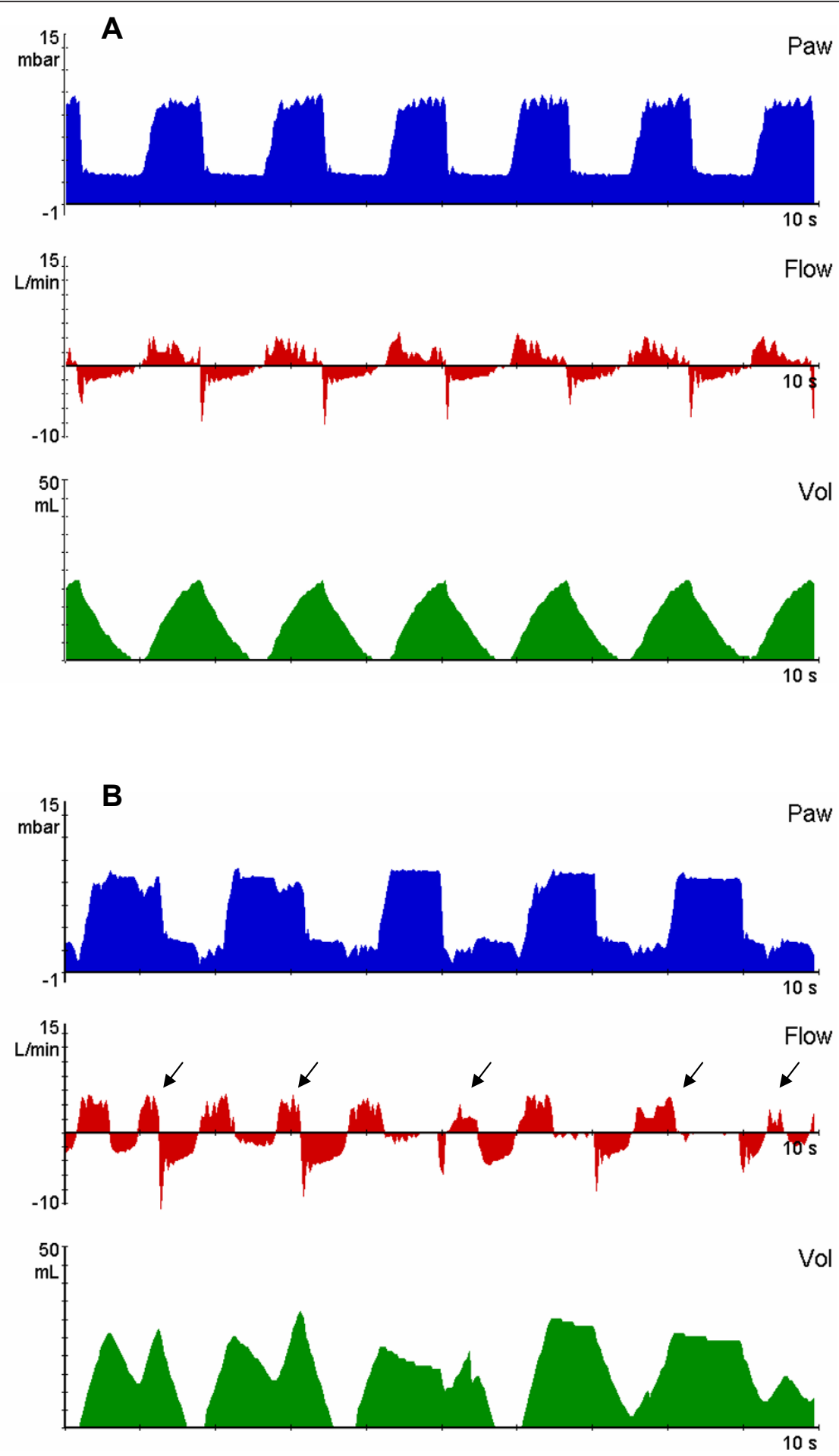

Figure 2 Representative recordings of airway pressure (Paw), flow and volume (Vol) in experimental groups. The upper panel (A) shows that the animal has no spontaneous breathing, the BIPAP is equal to PCV. The mechanical RR was 37 breaths/minute, and the Pmean was 5 $\mathrm{CmH}_{2} \mathrm{O}$. The lower panel (B) shows that non-supported spontaneous breathings (black arrows) were possible during each phase of the ventilatory cycle. The mechanical RR was set at 30 breaths/minute, total RR was 40 breaths/min and the Pmean was also $5 \mathrm{cmH}_{2} \mathrm{O}$. A and B had equal I:E ratio (1:1), $\mathrm{P},\left(8 \mathrm{cmH}_{2} \mathrm{O}\right)$ and PEEP $\left(2 \mathrm{cmH}_{2} \mathrm{O}\right)$. BIPAP, biphasic positive airway pressure; I:E, inspiratory-to-expiratory ratio; PCV, pressure control ventilation; PEEP, positive end-expiration pressure; $\mathrm{P}_{\mathrm{l}}$, inspiratory pressure; Pmean, mean airway pressure; RR, respiratory rate. 
adjusted to maintain the rate of non-supported spontaneous breathing within 3 to 15 breaths/minute.

Mean airway pressure (Pmean) for the BIPAP mode can be calculated by [29]:

$$
\text { mean airway pressure }=\frac{\mathrm{P}_{1} \times \mathrm{T}_{1}+\mathrm{PEEP} \times \mathrm{T}_{\mathrm{E}}}{\mathrm{T}_{1}+\mathrm{T}_{\mathrm{E}}} \text {. }
$$

Here, $T_{I}$ is the length of time for which $P_{I}$ is maintained; $\mathrm{T}_{\mathrm{E}}$ is the length of time during which PEEP is held. If the ratio of $T_{I}$ to $T_{E}$ is fixed at $1: 1$, then the Pmean could be kept constant when we changed the cycle frequency from $\mathrm{P}_{\mathrm{I}}$ to PEEP (or RR). Using this to adjust ventilator parameters (detailed above), we could keep the level of ventilatory support (Pmean) comparable between SB group and CV group of rabbits in our study. Thereafter, the sole difference between the SB group and CV group was whether or not the animals had their spontaneous breathing preserved (Figure 2).

\section{Measurements and calculations}

Arterial pressure, heart rate, central vein pressure and ventilatory parameters were continuously measured each hour. An in-line pressure differential pneumotachometer $\left(\mathrm{CO}_{2} \mathrm{SMO}\right.$ Puls; Novametrix Medical Systems, Wallingford, CT, USA) was used to measure end-tidal $\mathrm{CO}_{2}$ $\left(\mathrm{ETCO}_{2}\right)$, tidal volume, spontaneous tidal volume, spontaneous respiratory rate, total minute volume, spontaneous minute volume, mean airway pressure and peak airway pressure. The ratio of alveolar dead space to tidal volume (VD/VT) was calculated by [30]: VD/VT = $\left(\mathrm{PaCO}_{2}-\mathrm{ETCO}_{2}\right) / \mathrm{PaCO}_{2}$.

At baseline and at the end of eight hours of MV, we measured static lung compliance (Cs). Before measurement, we used Pipecuronium Bromide $(0.3 \mathrm{mg} / \mathrm{kg})$ to depress the animals' spontaneous breathing. Thus, the BIPAP mode was equal to PCV mode: Inspiratory pressure $\left(\mathrm{P}_{\mathrm{I}}\right)$ and PEEP were not changed; inspiration time was set to five seconds; expiration time was prolonged to allow the expiratory flow to return to zero; and the expiratory tidal volume (VTexp) was recorded. The calculation for $\mathrm{Cs}$ used the following formula: $\mathrm{Cs}=$ $\mathrm{VTexp} /\left(\mathrm{P}_{\mathrm{I}}\right.$-PEEP) [31].

Arterial blood gas samples were obtained at baseline, and at one, two, four, six and eight hours after randomization. Arterial blood gas variables were determined by an ABL 725 analyzer (Radiometer, Copenhagen, Denmark), including $\mathrm{pH}, \mathrm{PaCO}_{2}, \mathrm{PaO}_{2}, \mathrm{HCO}_{3}{ }^{-}$, and lactic acid.

\section{Bronchoalveolar lavage}

Sterile normal saline $(10 \mathrm{ml})$ was used to lavage the left lower lobes. After five seconds, the lavage liquid was recycled. The return volume was 5 to $6 \mathrm{ml}$. These samples were immediately centrifuged at 3,000 to 4,000 rpm for 15 minutes. Supernatant aliquots were kept frozen at $-40^{\circ} \mathrm{C}$ for subsequent analysis.

\section{Blood measurements}

Using ethylenediaminetetraacetic acid (EDTA), venous blood samples $(5 \mathrm{ml})$ from a central vein were obtained at baseline, and at two, four, six and eight hours after randomization. These were immediately centrifuged at 3,000 to $4,000 \mathrm{rpm}$ for 15 minutes. Serum was kept frozen at $-40^{\circ} \mathrm{C}$ for subsequent analysis.

\section{Cytokine and protein measurements}

BALF, serum and lung homogenate concentrations of IL-6, IL-1 $\beta$, IL-10, TNF- $\alpha$, and MIP-2 were determined using commercial enzyme-linked immunosorbent assay (ELISA) kits for rabbits (Rapidbio, Calabasas, CA, USA). All ELISAs were done by the same technician according to the manufacturers' guidelines. Total protein levels in BALF were determined using a Bradford Protein Assay Kit (Sun Biomedical Technology, Beijing, China) according to the manufacturers' instructions with BSA as standard.

Cytokine mRNA analysis by quantitative real-time reverse transcription polymerase chain reaction (RT-PCR)

Total RNA was extracted from lung tissue with a Trizol Isolation Kit (Sun Biomedical Technology) according to the manufacturer's protocol. Initially, the left upper lung tissue maintained in liquid nitrogen was placed in lysis buffer, then immediately disrupted and homogenized using a rotor-stator homogenizer. About 50 to $100 \mathrm{mg}$ of material was used for RNA isolation with $1 \mathrm{ml}$ of Trizol reagent. M-MLV reverse transcriptase (Sun Biomedical Technology) and oligo-(dT) 12 to 18 primers (Sun Biomedical Technology) were used to generate total cDNA. PCR was performed with a reaction volume of $50 \mu \mathrm{l}$ using a BioEasy SYBR Green I Real Time PCR Kit (Sun Biomedical Technology) according to the manufacturer's instructions. As an internal control, glyceraldehyde-3-phosphate dehydrogenase (GADPH) primers were used for RNA template normalization. The results obtained from real-time RT-PCR were quantified by the $2^{-\Delta \Delta \mathrm{Ct}}$ method, as previously reported [32,33]. Each sample was tested in triplicate. The sense $(\mathrm{S})$ and antisense (AS) of the primers (5'-3') used for each cytokine were:

TNF- $\alpha:$ AGCGCCATGAGCACTGAGA/
GCCACGAGCAGGAAGAGAA
IL-6: AGCCCGACTATGAACTCCTTCAC/
CCGGATGCTCTCGATGGT
IL-10: AGAACCACAGTCCAGCCATCA/
GCTTGCTGAAGGCGCTCTT




\section{IL-1 $\beta$ : GCAGACGGGAAACAGATTGTG/ TTGCCTGAATGGCAGAGGTAA}

\section{Lung histopathology}

Samples from the central parts of four different right lobes of the all animals were selected for histopathology examinations. Each sample was sectioned, stained with hematoxylin and eosin, and scored by a pathologist blinded to the experimental design. A lung injury score for each lung section was evaluated using a VILI histopathology scoring system as previously described [34]. The VILI scoring system included four items: alveolar congestion; hemorrhage; infiltration and aggregation of neutrophils in airspace or vessel wall; and thickness of alveolar wall/hyaline membrane formation. The VILI scoring system was graded from 0 (normal lung) to 4 (very severe involvement in $>75 \%$ of the lung). Thus, the total score for each section ranged from 0 to 16 . The overall lung injury score for each animal was the average score of the four sections from each right lobe.

\section{Statistical analysis}

Data are given as mean \pm SD or median (interquartile range), as appropriate. The normality of data distributions was assessed with a Kolmogorov-Smirnov test, and the homogeneity of variances was tested with Levene's test. Differences among groups were analyzed by oneway analysis of variance (ANOVA). Continuous variables, including hemodynamics, blood gases, respiratory parameters and cytokines level, were compared using repeated measures ANOVA. Logarithmic transformations of cytokine levels in BALF and serum were made before using parametric tests. $P$-values $<0.05$ were considered significant. All analyses used SPSS 11.5 (SPSS Inc., Chicago, IL, USA).

\section{Results}

\section{Hemodynamics and gas exchange}

The mean arterial blood pressures (MBP) within both the control ventilation $(\mathrm{CV})$ and spontaneous breathing (SB) groups were similar and were maintained at the expected levels during the entire experiment (Table 1). Heart rate and central venous pressure remained stable during the experiment, and there were no differences for these two variables between SB group and CV group (Table 1). Both groups received equal administrations of fluid boluses. No other drugs were needed to maintain hemodynamic conditions.

The $\mathrm{pH}$ values of all animals were greater than 7.2 during the experiment without the administration of sodium bicarbonate; however, after eight hours of ventilation, the SB group had a higher mean $\mathrm{pH}$ value (7.33 $\pm 0.08)$ than the CV group $(7.24 \pm 0.05)$ (Table 1 ). $\mathrm{PaCO}_{2}$ values of all animals were maintained within the range noted in Methods, although $\mathrm{PaCO}_{2}$ values were higher in the $\mathrm{CV}$ group compared to the $\mathrm{SB}$ group after randomization, and this difference was significantly different between the groups after six hours of ventilation; $\mathrm{PaCO}_{2}$ values in the SB group reduced significantly after

Table 1 Physiology response to spontaneous breathing (SB Group) and control ventilation (CV group).

\begin{tabular}{|c|c|c|c|c|c|c|}
\hline & \multicolumn{3}{|c|}{ Time $=0 \mathrm{~h}$} & \multicolumn{3}{|c|}{ Time $=8 \mathrm{~h}$} \\
\hline & $\begin{array}{c}\text { CV group } \\
(n=8)\end{array}$ & $\begin{array}{c}\text { SB group } \\
(n=8)\end{array}$ & $P_{1}$ & $\begin{array}{l}\text { CV group } \\
(n=8)\end{array}$ & $\begin{array}{c}\text { SB group } \\
(n=8)\end{array}$ & $P_{2}$ \\
\hline HR (breaths/minute) & $232.2 \pm 23.7$ & $239.3 \pm 28.2$ & 0.66 & $219.3 \pm 19.8$ & $235.2 \pm 21.7$ & 0.22 \\
\hline $\mathrm{MBP}(\mathrm{mmHg})$ & $89.0 \pm 11.0$ & $91.4 \pm 16.5$ & 0.75 & $92.6 \pm 17.8$ & $90.7 \pm 9.4$ & 0.81 \\
\hline CVP (mmHg) & $3.6 \pm 0.7$ & $3.7 \pm 0.7$ & 0.74 & $3.6 \pm 0.5$ & $3.9 \pm 0.6$ & 0.41 \\
\hline VT (ml/kg) & $12.9 \pm 0.8$ & $12.3 \pm 1.7$ & 0.54 & $12.2 \pm 1.4$ & $13 \pm 0.6$ & 0.24 \\
\hline VTspont (ml/kg) & 0 & 0 & - & 0 & $10.9 \pm 0.8$ & - \\
\hline $\mathrm{RR}_{\mathrm{TOT}}$ (breaths/minute) & $38.3 \pm 4.1$ & $37.5 \pm 2.7$ & 0.69 & $45.0 \pm 4.5$ & $39.5 \pm 7.4$ & 0.15 \\
\hline RRspont (breaths/minute) & 0 & 0 & - & 0 & $8.8 \pm 5.4$ & - \\
\hline $\mathrm{MV}_{\text {TOT }}(\mathrm{L} /$ minute $)$ & $1.26 \pm 0.28$ & $1.04 \pm 0.23$ & 0.18 & $1.50 \pm 0.26$ & $1.18 \pm 0.33$ & 0.10 \\
\hline $\mathrm{P}_{1}\left(\mathrm{cmH}_{2} \mathrm{O}\right)$ & $8 \pm 1.6$ & $8 \pm 1.5$ & 1.00 & $9 \pm 0.6$ & $8.3 \pm 1.8$ & 0.43 \\
\hline Pmean $\left(\mathrm{cmH}_{2} \mathrm{O}\right)$ & $4.67 \pm 0.8$ & $4.67 \pm 0.5$ & 1.00 & $5.33 \pm 0.8$ & $5.00 \pm 0.6$ & 0.45 \\
\hline Compliance $\left(\mathrm{ml} / \mathrm{cmH}_{2} \mathrm{O}\right)$ & $5.4 \pm 0.7$ & $5.55 \pm 2.6$ & 0.87 & $4.3 \pm 0.8$ & $7.6 \pm 2.4^{*}$ & 0.01 \\
\hline Arterial pH & $7.34 \pm 0.08$ & $7.38 \pm 0.06$ & 0.27 & $7.24 \pm 0.05^{*}$ & $7.33 \pm 0.08$ & 0.04 \\
\hline $\mathrm{PaCO}_{2}(\mathrm{mmHg})$ & $48.5 \pm 8.7$ & $43.9 \pm 6.2$ & 0.32 & $51.5 \pm 7.8$ & $38.2 \pm 7.1^{*}$ & 0.01 \\
\hline $\mathrm{PaO}_{2} / \mathrm{FiO}_{2}(\mathrm{mmHg})$ & $399.0 \pm 46.4$ & $430.3 \pm 40.0$ & 0.24 & $437.7 \pm 60.3$ & $476.3 \pm 11.6$ & 0.40 \\
\hline Lactic acid (mmol/L) & $1.0 \pm 0.2$ & $1.4 \pm 0.4$ & 0.10 & $2.1 \pm 0.4$ & $1.7 \pm 0.7$ & 0.70 \\
\hline
\end{tabular}

Results are given as mean $\pm \mathrm{SD}$. ${ }^{*} P<0.05$ compared with baseline within the same group. $P_{1}$, compared between SB group and $\mathrm{CV}$ group at $0 \mathrm{~h}$; $P_{2}$, compared between SB group and CV group at $8 \mathrm{~h}$. CVP, central venous pressure; $\mathrm{FiO}_{2}$, fraction of inspired oxygen; HR, heart rate; MBP, mean arterial pressure; $\mathrm{MV} \mathrm{T}_{\mathrm{TO}}$, total minute volume; $\mathrm{PaCO}_{2}$, arterial partial pressure of carbon dioxide; $\mathrm{PaO}_{2}$, arterial partial pressure of oxygen; $\mathrm{P}_{1}$, inspiratory pressure; Pmean, mean airway pressure; RRspont, non-supported spontaneous respiratory rate; $\mathrm{RR}_{\mathrm{TOT}}$, total respiratory rate; $\mathrm{VT}$, tidal volume; VTspont, tidal volume of non-supported spontaneous breathing. 
randomization $(P<0.05$; Figure 3$)$. Both groups had similar $\mathrm{PaO}_{2} / \mathrm{FiO}_{2}$ ratios (Figure 3).

The total respiratory frequency $\left(\mathrm{RR}_{\mathrm{TOT}}\right)$ and total minutes of ventilation $\left(\mathrm{MV}_{\mathrm{TOT}}\right)$ were stably maintained for both groups of rabbits, with no significant differences between the groups (Table 1). However, the ratio of dead space to tidal volume in the SB group decreased gradually after randomization, and showed a significant difference between SB group and CV group after eight hours (Figure 3).

\section{Respiratory mechanics}

Rabbits in the SB group and the CV group had similar Pmean and $\mathrm{P}_{\mathrm{I}}$ throughout the experiment (Table 1). Both groups had similar static lung compliances (Cs) at baseline. However, the Cs values of the SB group markedly increased and were significantly higher than in the
CV group after eight hours of ventilation (Table 1). Conversely, the $\mathrm{Cs}$ values of the $\mathrm{CV}$ group slightly decreased by the end of the experiment.

\section{Total protein levels in BALF}

Total BALF protein levels in CV group were significantly higher as compared with control animals $(P<$ 0.05; Figure 4). No significant difference was found between the SB group and control animals. Total BALF protein levels were slightly lower in the SB group than in the CV group $(41.8 \pm 34.1$ vs $69.2 \pm 38.3 \mu \mathrm{g} / \mathrm{ml}, P=$ 0.112).

Cytokine levels in serum, bronchoalveolar lavage fluid (BALF) and lung homogenate

There were no differences in serum TNF- $\alpha$, IL- 6 , IL- $1 \beta$, IL-10 or MIP- 2 concentrations between the SB group
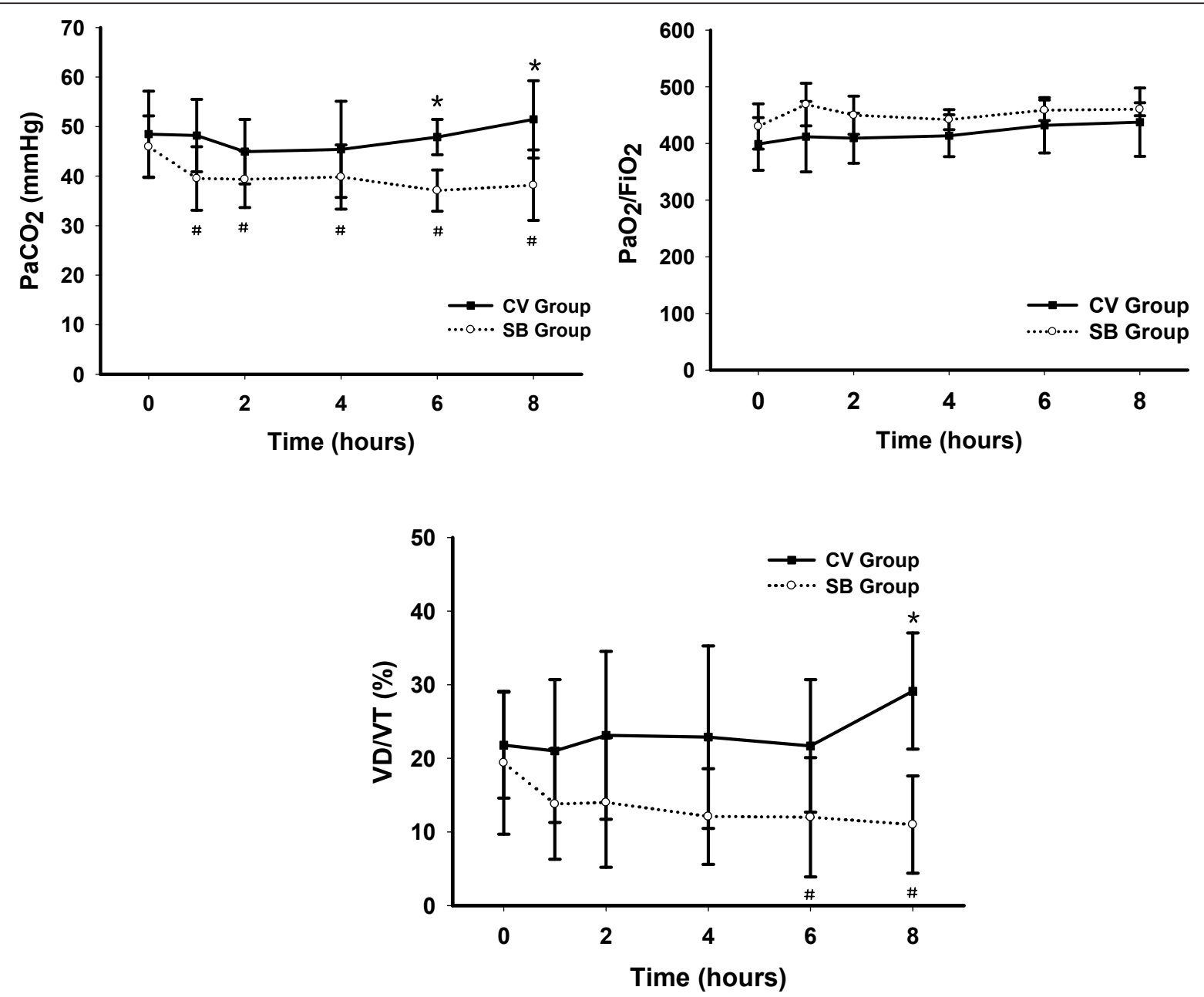

Figure 3 Time course for $\mathrm{PaCO}_{2}, \mathrm{PaO}_{2} / \mathrm{FiO}_{2}$ and VD/VT in experimental groups. Results are given as mean $\pm \mathrm{SD}$. ${ }^{*} P<0.05$ between groups at the same time. ${ }^{\#} P<0.05$ compared with baseline within the same group. $\mathrm{CV}$, control ventilation; $\mathrm{FiO}_{2}$, fraction of inspired oxygen; $\mathrm{PaCO}_{2}$, arterial partial pressure of carbon dioxide; $\mathrm{PaO}_{2}$, arterial partial pressure of oxygen; $\mathrm{SB}$, spontaneous breathing; VDNT, ratio of alveolar dead space to tidal volume. 


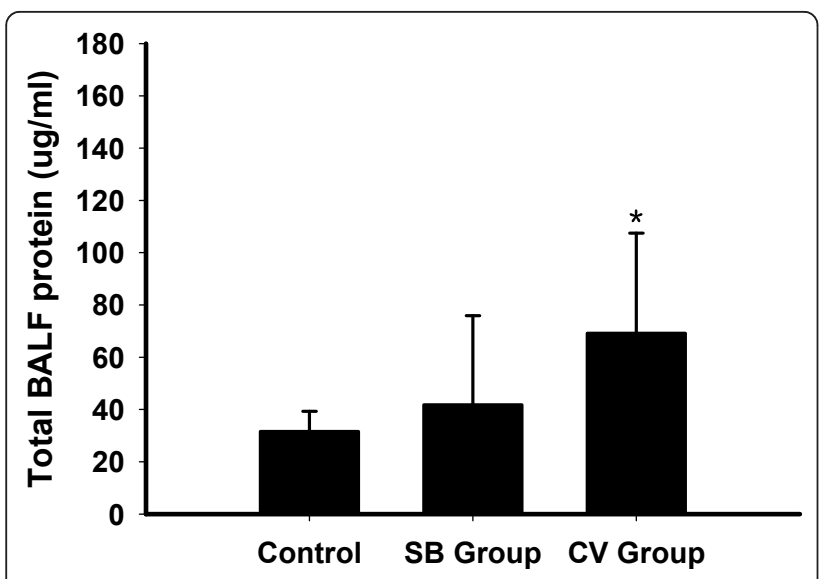

Figure 4 Total BALF protein in non-ventilated (control) and experimental groups. Results are given as mean \pm SD. $* P<0.05$ compared with control animals. BALF, bronchoalveolar lavage fluid; $\mathrm{CV}$, control ventilation; SB, spontaneous breathing.

and $\mathrm{CV}$ group during the entire experiment (Figure 5). There were also no significant differences within each group at baseline and at the end of the experiment. We also did not find any differences between the CV group and SB group for any of the cytokines in BALF (TNF- $\alpha$, $4.29 \pm 1.52$ vs $3.78 \pm 1.5 \mathrm{pg} / \mathrm{ml} ; \mathrm{IL}-6,31.3 \pm 12.1 \mathrm{vs}$ $26.6 \pm 11.7 \mathrm{pg} / \mathrm{ml} ; \mathrm{IL}-1 \beta, 11.5 \pm 5.6$ vs $9.16 \pm 5.6 \mathrm{pg} / \mathrm{ml} ;$ IL-10, $48.34 \pm 6.17$ vs $54.2 \pm 9.5 \mathrm{pg} / \mathrm{ml}$ ) (Figure 6). The cytokines (TNF- $\alpha$, IL- 6 and IL-1 $\beta$ ) level of lung homogenates in the CV group and the SB group were slightly higher than control animals $(P>0.05)$, but IL-10 concentrations in the $\mathrm{CV}$ group were significantly higher than control animals $(P<0.05)$. Pulmonary levels of IL6, IL- $1 \beta$, IL-10 and TNF- $\alpha$ between the CV group and the SB group were comparable (Figure 7).

\section{Cytokines' mRNA expressions in lung tissue}

The expressions of IL- 6 , IL- $1 \beta$, IL-10 and TNF- $\alpha$ mRNA in lung tissues were evidently higher in the $\mathrm{CV}$ group compared to the SB group and control animals ( $P$ $<0.05$; Figure 8). The TNF- $\alpha$ mRNA expression was six times higher in the $\mathrm{CV}$ group than in the SB group $(P=$ 0.001). The other cytokines' mRNA expressions were about two times higher in the CV group as compared to the SB group. No significant difference was found between the SB group and control animals.

\section{Lung histopathological injury}

Gross histological evaluations of the right lower lobe lungs showed that the SB group had nearly normal lung tissue, whereas the $\mathrm{CV}$ group showed greater alveolar collapse, thickness of the alveolar septum, alveolar capillary congestion, and inflammatory cell migration (Figure 9). Also, the average lung histological injury score of the whole right lung was higher in the CV group $(5.7 \pm 1.0)$ as compared to the SB group $(3.7 \pm 1.7, P=0.005)$ and control animals $(1.7 \pm 1.0, P<0.001$; Figure 9$)$. The average lung histological injury score were also higher in the SB group than in control animals $(P=0.005)$.

\section{Discussion}

To our knowledge, this is the first study on the effects of spontaneous breathing on VILI in the mechanicallyventilated healthy lung. We found that preserving spontaneous breathing during MV could not only improve ventilatory function, but could also attenuate selected markers of VILI.

For our experiments, we selected tidal volume of as large as 10 to $15 \mathrm{ml} / \mathrm{kg}$ to ventilate animals with healthy lungs. Hong et al. [33] found that a moderate tidal volume $(15 \mathrm{ml} / \mathrm{kg})$ and low PEEP $\left(3 \mathrm{cmH}_{2} \mathrm{O}\right)$ resulted in lower inflammatory response expressions in lung tissue and lung injury than with a small tidal volume $(6 \mathrm{ml} / \mathrm{kg})$ and high PEEP $\left(10 \mathrm{cmH}_{2} \mathrm{O}\right)$ in a healthy animal model. Thus, we set PEEP to $2 \mathrm{cmH}_{2} \mathrm{O}$ to avoid excessive distension of alveoli and concomitantly prevent alveolar collapse at end-expiration. In addition, we applied a biphasic positive airway pressure (BIPAP) mode during $\mathrm{MV}$, which allowed animals to breathe freely at any phase of the mechanical ventilatory cycle. When rabbits did not exhibit spontaneous breathing, the BIPAP mode was equal to the pressure control ventilation (PCV) mode. Pmean, which reflects the average level of alveolar pressure during the entire respiratory cycle, is also an important factor contributing to the development of lung injury [35]. In our study, the Pmean between the $\mathrm{SB}$ group and the CV group was comparable by the method of adjusting ventilator settings (detailed in Materials and methods).

We demonstrated that control ventilation caused higher dead space ventilation (VD/VT) than preserving spontaneous breathing during positive pressure MV. Putensen et al. [15] also found that spontaneous breathing could improve dead space ventilation in mechanically-ventilated patients with acute respiratory distress syndrome. This phenomenon may be explained by considering that preserving respiratory muscle contraction favors more ventilation to dependent lung regions [12-14], reduces atelectasis [12,20], and improves ventilation-perfusion matching $[14,15]$. On histopathology examinations, we also found that more alveolar collapse appeared in our CV group.

Furthermore, we showed that preserving spontaneous breathing was followed by a lower $\mathrm{PaCO}_{2}$ than control ventilation after eight hours of $\mathrm{MV}$, while other studies $[15,17]$ did not find differences between the SB and CV groups in $\mathrm{PaCO}_{2}$. These differences may be attributed to the number of hours of control ventilation. The previous studies used only two hours of control ventilation, 

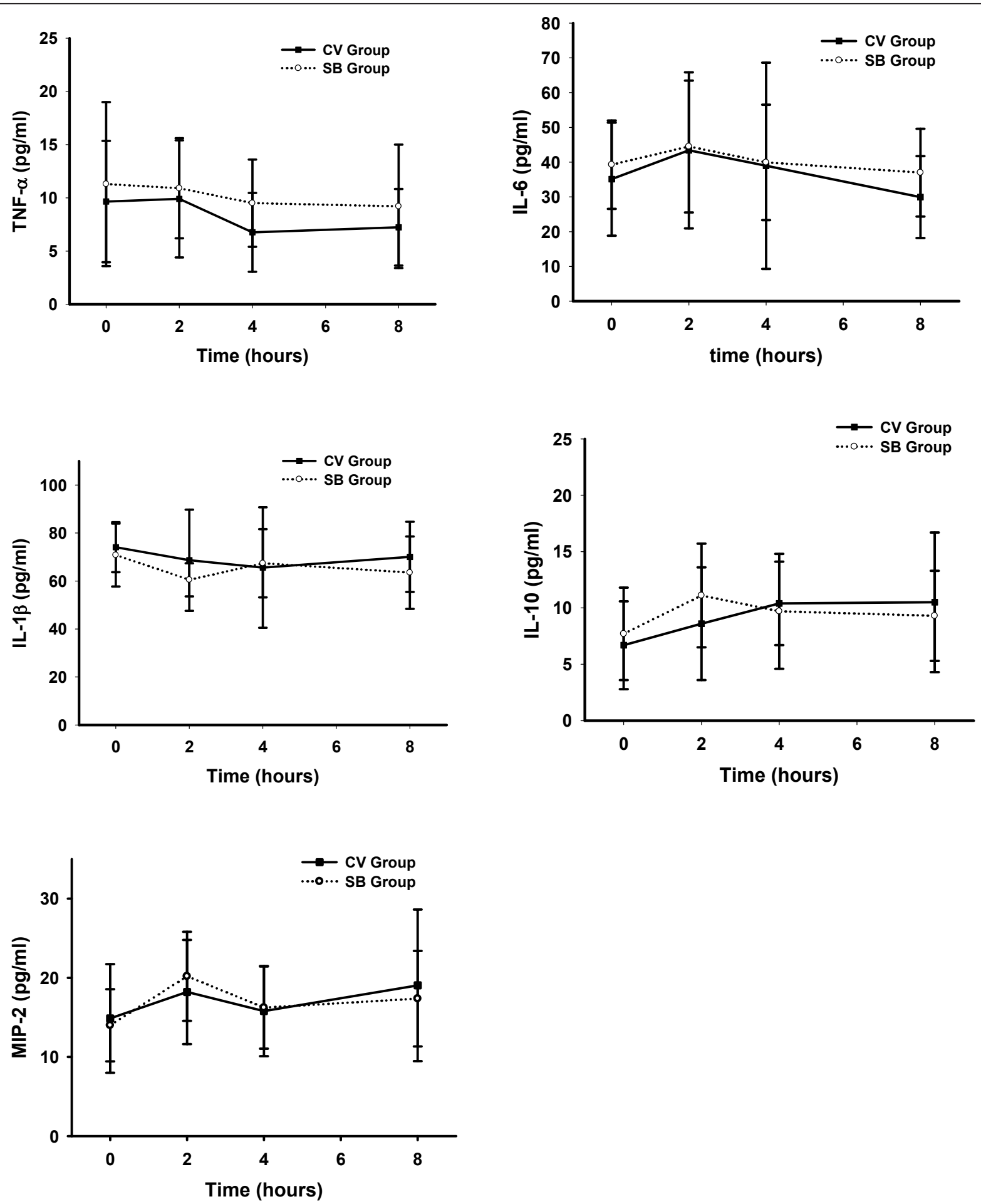

Figure 5 Time course for the serum concentration of different cytokines in experimental groups. Results are given as mean \pm SD. CV, control ventilation; SB, spontaneous breathing.

while our study used eight hours. We also did not find any significant differences in the first two hours of MV after randomization, however, after six hours, there was a difference and this was notable.
Although spontaneous breathing could obviously improve ventilatory function after a long time of MV, there was no difference between the SB and CV groups on oxygenation, which is in contrast to other reports 


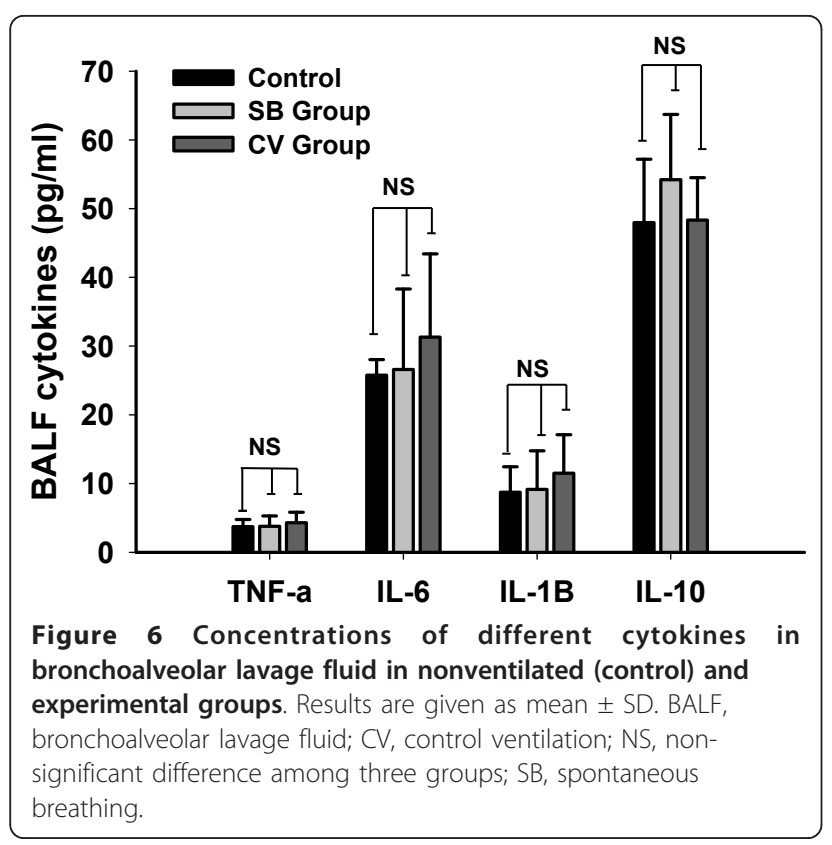

$[12,15]$. Wrigge et al. [12] found that preserving spontaneous breathing resulted in better oxygenation compared to control ventilation in an acute lung injury model with MV. It is possible that there is less alveolar collapse and lung injury in a normal lung model than an acute lung injury model.

Preserving spontaneous breathing can reduce atelectasis and improve gas distribution in the ventilatory-supported normal lung. However, prior to this study, we could not clearly identify the effects of spontaneous breathing on VILI in the normal lung. In our study, we demonstrated that there were no differences between the SB group and the CV group in the concentrations of all the measured cytokines in serum and BALF. However, animals with spontaneous breathing showed significantly lower gene expression levels of inflammatory cytokines (TNF- $\alpha$, IL-6, IL-1 $\beta$ ) and anti-inflammatory cytokine (IL-10) in lung tissues. Furthermore, the gene expression levels of cytokines in SB group were similar to control animals. The level of IL-10 in the SB group was parallel decreased, since it has anti-inflammatory
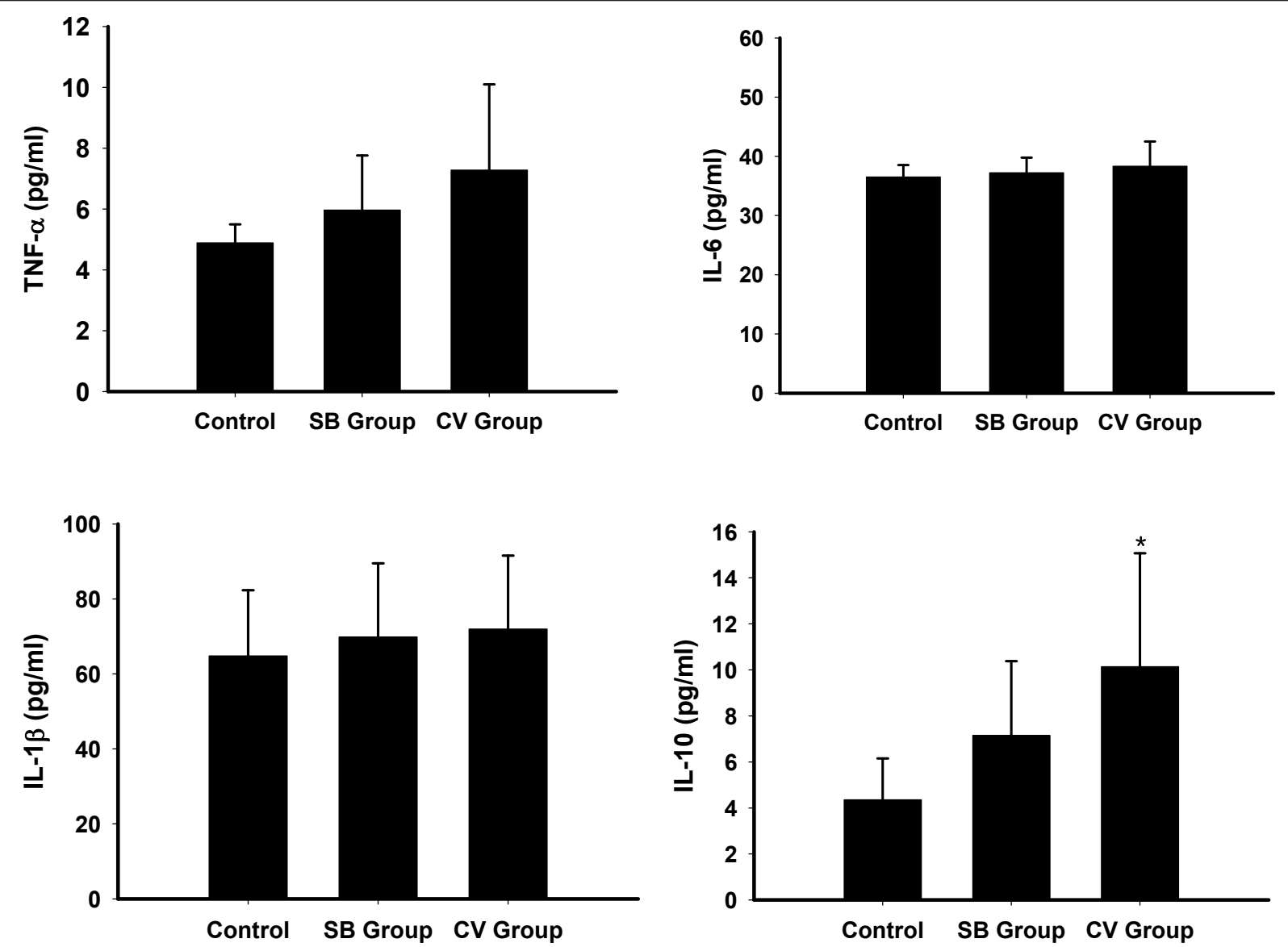

Figure 7 Pulmonary level of different cytokines in nonventilated (control) and experimental groups. Results are given as mean \pm SD. ${ }^{*} P$ $<0.05$ compared with control animals. CV, control ventilation; SB, spontaneous breathing; 


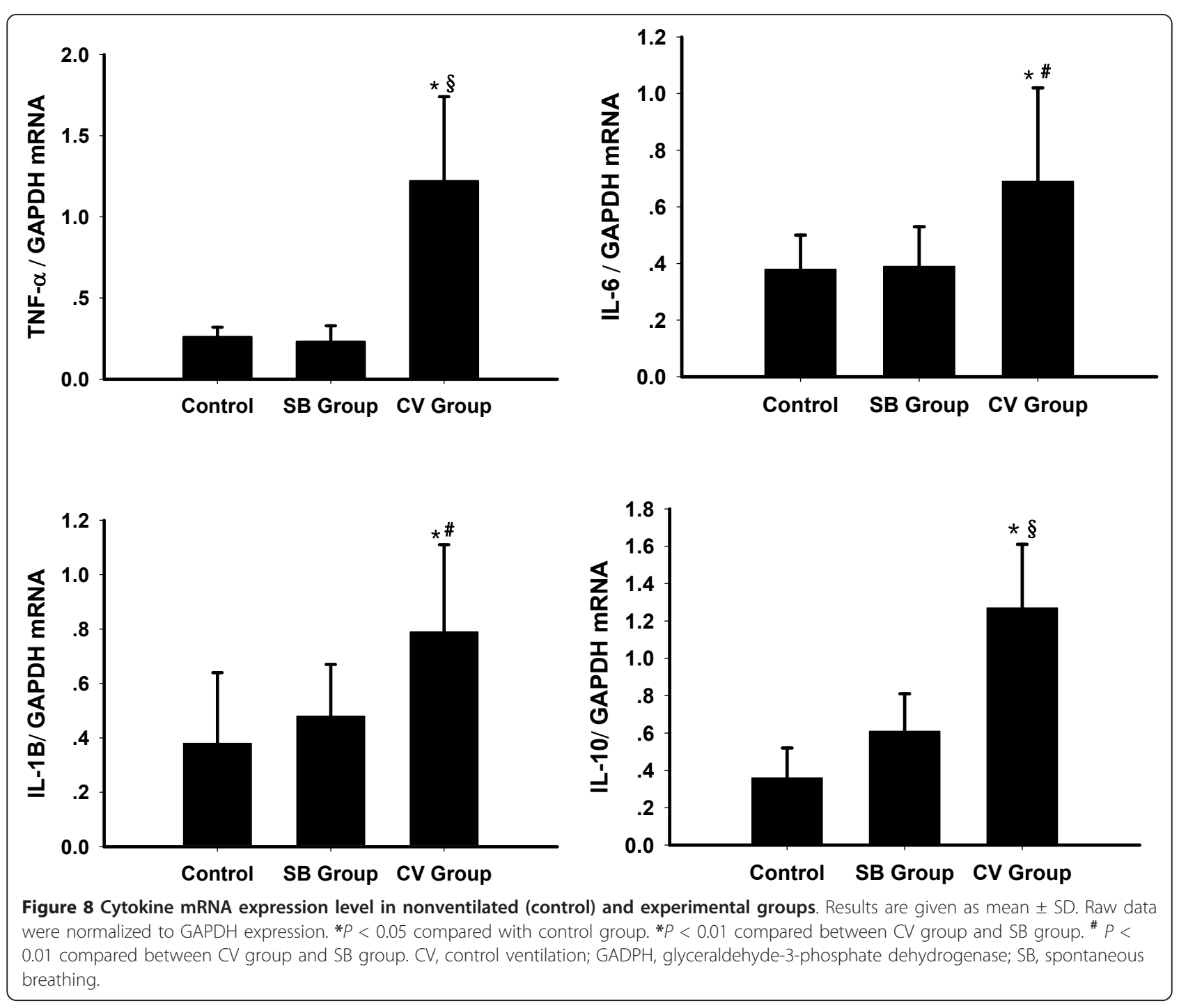

properties. It was suggested that the inflammatory response was significantly reduced in lung tissues. TNF$\alpha$ mRNA expression was six times higher in our $\mathrm{CV}$ group than in our SB group. The mRNA levels of other cytokines (IL-6, IL-1 $\beta$, and IL-10) were about two times higher in the CV group compared to the SB group. Moreover, we also found total protein levels in BALF were slightly lower in the SB group than in the $\mathrm{CV}$ group. Maybe cytokines were already expressed in alveolar epithelial cells, but had not yet migrated into the alveolar lumen or systemic circulation, because we found that the cytokines level in lung homogenate increased slightly in the CV group, especially antiinflammatory cytokine (IL-10). With an extended time of control MV, inflammatory responses may be further aggravated and lead to increased cytokine levels in the alveolar lumen and systemic circulation.
Consistent with the inflammatory responses, the histopathological damage to lung tissue was more severe in animals with control ventilation than in those with spontaneous breathing. To compare lung injury of the whole right lung of all animals, we selected the central parts of four different right lobes for histopathology examination and did not divide the right lung into nondependent and dependent parts. The pathological changes in the animals of our CV group agree with the changes seen in healthy animals with similar ventilator settings in other studies $[33,36]$. Control ventilation can cause more alveolar collapse and congestion, thickening of the alveolar septum, and infiltrations of inflammatory cells into lung tissue. Lung histological scores also showed that lung injury was more severe in animals with control ventilation. Our histological findings were in accord with previous studies [26,27] which 

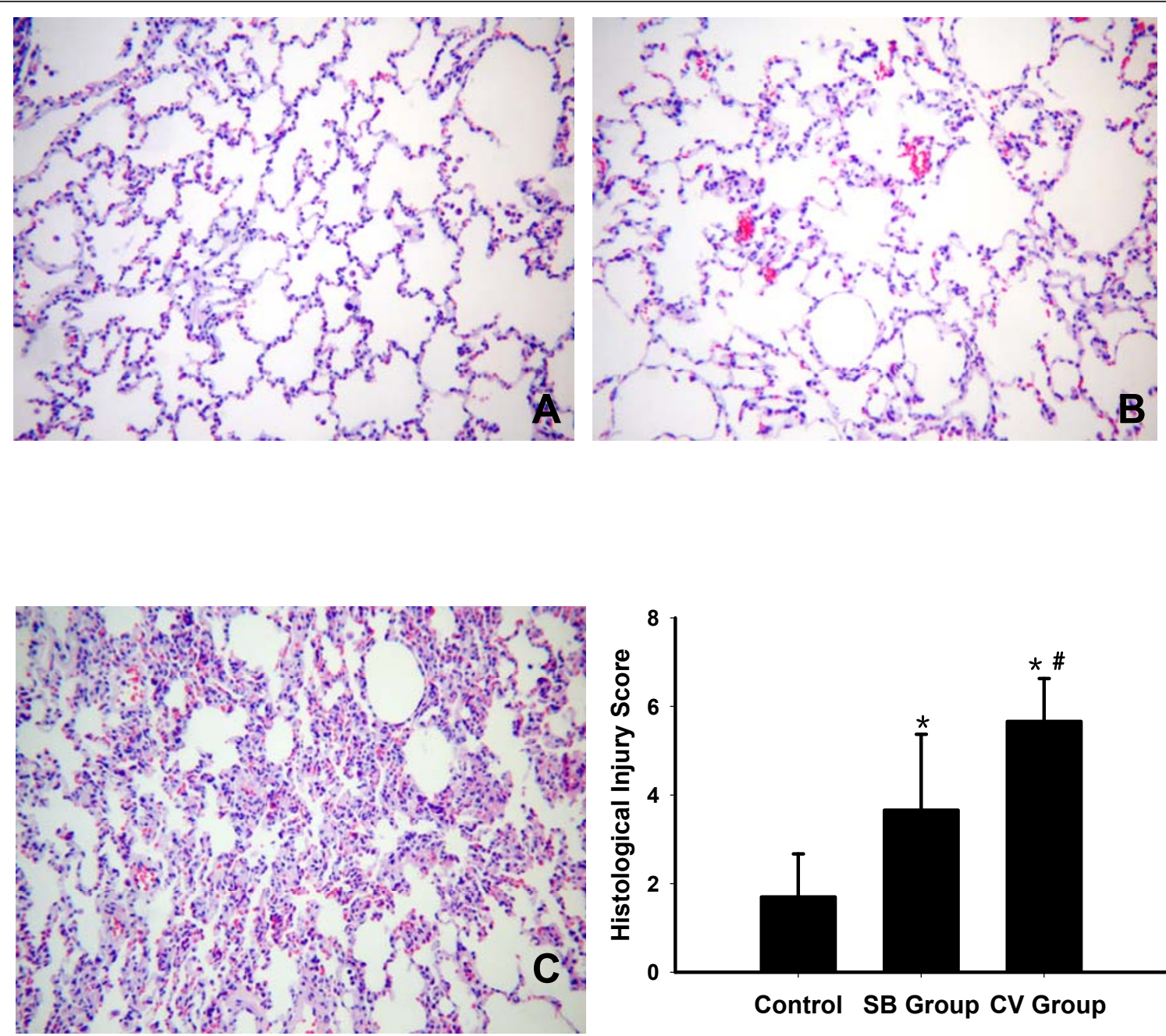

Figure 9 Representative photomicrographs of the right lower lobe and the lung injury score from nonventilated (control) and experimental groups. The upper panel shows photomicrographs of hematoxylin-eosin-stained lung sections (magnification $\times 100)$ of right lower lobe in control animals (A), SB group (B) and CV group (C). SB group (B) with mild alveolar congestion. CV group (C) with increased alveolar collapse and congestion, thickening of alveolar septum, alveolar capillary congestion, and inflammatory cell migration. The lower right panel shows the gradation of the VILI scoring system (detailed in Materials and methods) in SB group and CV group. Results are given as mean \pm SD. ${ }^{*} P<0.05$ compared with control groups. ${ }^{*} P<0.01$ compared between CV group and SB group. CV, control ventilation; SB, spontaneous breathing; VILI, ventilator-induced lung injury.

demonstrated that the assisted ventilation mode could reduce lung injury compared to the control ventilation mode in an acute lung injury model.

There are many factors that can attenuate VILI when spontaneous breathing is preserved during MV with a healthy lung: increased ventilation to dependent lung regions caused by an increase of transalveolar pressure, reduced occurrence of atelectasis, increased recruited lung volume $[17,20]$, improved compliance and further avoidance of atelectotrauma caused by the opening and closing of distal airways during tidal breaths $[37,38]$; more homogeneous distribution of gas, less dead space ventilation and hyperinflation [12,17]; redistribution of blood in alveolar capillaries, improved ventilation and perfusion matching [14]; variability of breathing patterns [25]; and physiological feedback and intrinsic defense mechanisms during spontaneous breathing, such as the Hering-Breuer reflex, may further prevent VILI.

Our study had several limitations. First, because our study animal model was healthy rabbits, we cannot directly extend our results to normal human lung function. Second, a larger VT of 10 to $15 \mathrm{ml} / \mathrm{kg}$ was selected in our study. It can cause lung injury in a previously healthy lung, as showed in CV group animals of our study. Therefore, it is necessary to design another similar study using smaller VT of 6 to $7 \mathrm{ml} / \mathrm{kg}$ to testify the protective effect of spontaneous breathing on VILI in healthy animals. Third, $\mathrm{PaCO}_{2}$ values were different 
between the SB group and the CV group, which could affect the experimental results of lung injury. Clinical and animal studies have shown that hypercapnic conditions had a protective effect against lung injuries, which were associated with significantly improved pulmonary edema, increased pulmonary compliance, and reduced levels of cytokines [39-41]. However, the CV group, with a higher $\mathrm{PaCO} 2$ than the SB group, did not exhibit a lower inflammatory response. It was further suggested that spontaneous breathing had a protective effect against VILI. Fourth, some invasive procedures can also have an impact on cytokine levels; thus, to guarantee comparable cytokine levels at baseline, surgical interventions were administrated by fixed researchers, who strictly controlled the time for our procedures and the amount of blood loss. Fifth, we did not measure transalveolar pressure to evaluate respiratory effort. Finally, SB group animals used less muscle relaxant (Pipecuronium Bromide) and anesthesia (Pentobarbital sodium). Unfortunately, it remains unknown if they can directly affect inflammatory responses.

\section{Conclusions}

In the present experimental study, we show that preserving spontaneous breathing during MV can not only improve ventilatory function, but can also attenuate selected markers of VILI in the healthy lung. However, our results cannot be extrapolated to humans, and clinical trials are necessary to confirm our results in humans.

\section{Key messages}

- Assuming comparable levels of ventilation support, preserving spontaneous breathing during MV is associated with better respiratory function as compared to control ventilation: both a lowered ratio of dead space ventilation to tidal volume and $\mathrm{PaCO}_{2}$.

- Compared to control ventilation, preserving spontaneous breathing can result in better lung compliance after eight hours of MV.

- Spontaneous breathing may have an important protective effect against VILI in mechanically ventilated healthy lung.

\footnotetext{
Abbreviations

ALI: acute lung injury; BAL: bronchoalveolar lavage; BALF: bronchoalveolar lavage fluid; BIPAP: biphasic positive airway pressure; BP: blood pressure; CV: control ventilation; CPAP: continuous positive airway pressure; Cs: static lung compliance; EDTA: ethylenediaminetetraacetic acid; ETCO2: end-tidal CO2; FiO2: fraction of inspired oxygen; GADPH: glyceraldehyde-3-phosphate dehydrogenase; HR: heart rate; IL: interleukin; MIP-2: macrophage inflammatory protein; mRNA: messenger ribonucleic acid; MV: mechanical ventilation; $\mathrm{MV}_{\text {TOT: }}$ : total minute ventilation; $\mathrm{PaCO}_{2}$ : arterial partial pressure of carbon dioxide; $\mathrm{PaO}_{2}$ : arterial partial pressure of oxygen; $\mathrm{PCV}$ : pressure control ventilation; PEEP: positive end-expiration pressure; $\mathrm{P}_{\mathrm{i}}$ : inspiration pressure; $P_{\text {high }}$ : high level continuous positive airway pressure; $P_{\text {low }}$ : low level continuous positive airway pressure; Pmean: mean airway pressure; RT-PCR:
}

real time reverse transcription polymerase chain reaction; RR: respiratory rate; $\mathrm{RR}_{\text {TOT: }}$ total respiratory rate; SB: spontaneous breathing; TNF-a: tumor necrosis factor alpha; VILI: ventilator-induced lung injury; (VDNT)alv: the ratio alveolar dead space to tidal volume; $\mathrm{VT}$ : tidal volume.

\section{Acknowledgements}

The authors thank Ms Wenhui Chen for her help with microscopy, Ms Jingyu Quan for her skilled technical assistance during the experiments, and Mr Yonglin Tang for his help with acquisition of data. This study was supported by the National Natural Science Foundation of China (project No. 30971311), the National Basic Research Program of China (project No. 2009C13522105) and Beijing Novel Star Program (project No. 2005B03).

\section{Authors' contributions}

JX participated in the design of the study and in the experiments, was involved in the data extraction as well as statistics, and drafted the manuscript. BS participated in the design of the study and helped to draft the manuscript. $\mathrm{HH}$ participated in the design of the study and in the experiments, and helped to draft the manuscript. $\mathrm{HZ}$ and $\mathrm{CW}$ participated in the design of the study and in the experiments. QZ participated in the design of the study, was involved in interpretation of the results and helped to draft the manuscript. All authors read and approved the final manuscript for publication.

\section{Competing interests}

The authors declare that they have no competing interests.

Received: 8 April 2011 Revised: 9 August 2011

Accepted: 21 October 2011 Published: 21 October 2011

\section{References}

1. Frank JA, Matthay MA: Science review: mechanisms of ventilator-induced injury. Crit Care 2003, 7:233-241.

2. Dreyfuss D, Saumon G: Ventilator-induced lung injury: lessons from experimental studies. Am J Respir Crit Care Med 1998, 157:294-323.

3. Chiumello D, Pristine G, Slutsky AS: Mechanical ventilation affects local and systemic cytokines in an animal model of acute respiratory distress syndrome. Am J Respir Crit Care Med 1999, 160:109-116.

4. Ranieri VM, Suter PM, Tortorella C, De Tullio R, Dayer JM, Brienza A, Bruno F, Slutsky AS: Effect of mechanical ventilation on inflammatory mediators in patients with acute respiratory distress syndrome: a randomized controlled trial. JAMA 1999, 282:54-61.

5. Ranieri VM, Giunta F, Suter PM, Slutsky AS: Mechanical ventilation as a mediator of multisystem organ failure in acute respiratory distress syndrome. JAMA 2000, 284:43-44

6. Imai $Y$, Parodo J, Kajikawa O, de Perrot M, Fischer S, Edwards V, Cutz E, Liu M, Keshavjee S, Martin TR, Marshall JC, Ranieri VM, Slutsky AS: Injurious mechanical ventilation and end-organ epithelial cell apoptosis and organ dysfunction in an experimental model of acute respiratory distress syndrome. JAMA 2003, 289:2104-2112.

7. Frank JA, Parsons PE, Matthay MA: Pathogenetic significance of biological markers of ventilator-associated lung injury in experimental and clinical studies. Chest 2006, 130:1906-1914.

8. Amato MB, Barbas CS, Medeiros DM, Magaldi RB, Schettino GP, LorenziFilho G, Kairalla RA, Deheinzelin D, Munoz C, Oliveira R, Takagaki TY, Carvalho CR: Effect of a protective-ventilation strategy on mortality in the acute respiratory distress syndrome. N Engl J Med 1998, 338:347-354

9. Ventilation with lower tidal volumes as compared with traditional tidal volumes for acute lung injury and the acute respiratory distress syndrome. The Acute Respiratory Distress Syndrome Network. N Engl J Med 2000, 342:1301-1308.

10. Villar J, Kacmarek RM, Perez-Mendez L, Aguirre-Jaime A: A high positive end-expiratory pressure, low tidal volume ventilatory strategy improves outcome in persistent acute respiratory distress syndrome: a randomized, controlled trial. Crit Care Med 2006, 34:1311-1318.

11. Froese $A B$, Bryan $A C$ : Effects of anesthesia and paralysis on diaphragmatic mechanics in man. Anesthesiology 1974, 41:242-255.

12. Wrigge $H$, Zinserling J, Neumann P, Defosse J, Magnusson A, Putensen C, Hedenstierna G: Spontaneous breathing improves lung aeration in oleic acid-induced lung injury. Anesthesiology 2003, 99:376-384. 
13. Wrigge H, Zinserling J, Neumann P, Muders T, Magnusson A, Putensen C, Hedenstierna G: Spontaneous breathing with airway pressure release ventilation favors ventilation in dependent lung regions and counters cyclic alveolar collapse in oleic-acid-induced lung injury: a randomized controlled computed tomography trial. Crit Care 2005, 9:R780-R789.

14. Neumann P, Wrigge H, Zinserling J, Hinz J, Maripuu E, Andersson LG, Putensen C, Hedenstierna G: Spontaneous breathing affects the spatial ventilation and perfusion distribution during mechanical ventilatory support. Crit Care Med 2005, 33:1090-1095.

15. Putensen C, Mutz NJ, Putensen-Himmer G, Zinserling J: Spontaneous breathing during ventilatory support improves ventilation-perfusion distributions in patients with acute respiratory distress syndrome. Am J Respir Crit Care Med 1999, 159:1241-1248.

16. Kaplan LJ, Bailey H, Formosa V: Airway pressure release ventilation increases cardiac performance in patients with acute lung injury/adult respiratory distress syndrome. Crit Care 2001, 5:221-226.

17. Tokics L, Hedenstierna G, Svensson L, Brismar B, Cederlund T, Lundquist $H$ Strandberg A: V/Q distribution and correlation to atelectasis in anesthetized paralyzed humans. J Appl Physiol 1996, 81:1822-1833.

18. Gayan-Ramirez G, Testelmans D, Maes K, Racz GZ, Cadot P, Zador E, Wuytack F, Decramer M: Intermittent spontaneous breathing protects the rat diaphragm from mechanical ventilation effects. Crit Care Med 2005, 33:2804-2809.

19. Levine S, Nguyen T, Taylor N, Friscia ME, Budak MT, Rothenberg P, Zhu J, Sachdeva R, Sonnad S, Kaiser LR, Rubinstein NA, Powers SK, Shrager JB: Rapid disuse atrophy of diaphragm fibers in mechanically ventilated humans. N Engl J Med 2008, 358:1327-1335.

20. Hedenstierna G, Tokics L, Lundquist $H$, Andersson T, Strandberg A, Brismar B: Phrenic nerve stimulation during halothane anesthesia. Effects of atelectasis. Anesthesiology 1994, 80:751-760.

21. Sarge T, Talmor D: Targeting transpulmonary pressure to prevent ventilator induced lung injury. Minerva Anestesiol 2009, 75:293-299.

22. Lopez-Aguilar J, Piacentini E, Villagra A, Murias G, Pascotto S, SaenzValiente A, Fernandez-Segoviano P, Hotchkiss JR, Blanch L: Contributions of vascular flow and pulmonary capillary pressure to ventilator-induced lung injury. Crit Care Med 2006, 34:1106-1112.

23. Vaporidi K, Voloudakis G, Priniannakis G, Kondili E, Koutsopoulos A, Tsatsanis C, Georgopoulos D: Effects of respiratory rate on ventilatorinduced lung injury at a constant $\mathrm{PaCO} 2$ in a mouse model of normal lung. Crit Care Med 2008, 36:1277-1283.

24. Thille AW, Rodriguez P, Cabello B, Lellouche F, Brochard L: Patientventilator asynchrony during assisted mechanical ventilation. Intensive Care Med 2006, 32:1515-1522

25. Spieth PM, Carvalho AR, Guldner A, Kasper M, Schubert R, Carvalho NC, Beda A, Dassow C, Uhlig S, Koch T, Pelosi P, Gama De Abreu M: Pressure support improves oxygenation and lung protection compared to pressure-controlled ventilation and is further improved by random variation of pressure support. Crit Care Med 2011, 39:746-755.

26. Saddy F, Oliveira GP, Garcia CS, Nardelli LM, Rzezinski AF, Ornellas DS, Morales MM, Capelozzi VL, Pelosi P, Rocco PR: Assisted ventilation modes reduce the expression of lung inflammatory and fibrogenic mediators in a model of mild acute lung injury. Intensive Care Med 2010, 36:1417-1426.

27. Brander L, Sinderby C, Lecomte F, Leong-Poi H, Bell D, Beck J, Tsoporis JN, Vaschetto R, Schultz MJ, Parker TG, Villar J, Zhang H, Slutsky AS: Neurally adjusted ventilatory assist decreases ventilator-induced lung injury and non-pulmonary organ dysfunction in rabbits with acute lung injury. Intensive Care Med 2009, 35:1979-1989.

28. Walsh BK, Crotwell DN, Restrepo RD: Capnography/Capnometry during mechanical ventilation: 2011. Respir Care 2011, 56:503-509.

29. Frawley PM, Habashi NM: Airway pressure release ventilation: theory and practice. AACN Clin Issues 2001, 12:234-246.

30. Hardman JG, Aitkenhead AR: Estimating alveolar dead space from the arterial to end-tidal $\mathrm{CO}(2)$ gradient: a modeling analysis. Anesth Analg 2003, 97:1846-1851.

31. Grinnan DC, Truwit JD: Clinical review: respiratory mechanics in spontaneous and assisted ventilation. Crit Care 2005, 9:472-484.

32. Livak KJ, Schmittgen TD: Analysis of relative gene expression data using real-time quantitative PCR and the 2(-Delta Delta C(T)) Method. Methods 2001, 25:402-408.

33. Hong $C M, X u D Z$, Lu Q, Cheng $Y$, Pisarenko V, Doucet $D$, Brown $M$, Aisner S, Zhang C, Deitch EA, Delphin E: Low tidal volume and high positive end-expiratory pressure mechanical ventilation results in increased inflammation and ventilator-associated lung injury in normal lungs. Anesth Analg 2010, 110:1652-1660.

34. Wolthuis EK, Vlaar AP, Choi G, Roelofs JJ, Juffermans NP, Schultz MJ: Mechanical ventilation using non-injurious ventilation settings causes lung injury in the absence of pre-existing lung injury in healthy mice. Crit Care 2009, 13:R1.

35. Broccard AF, Hotchkiss JR, Suzuki S, Olson D, Marini JJ: Effects of mean airway pressure and tidal excursion on lung injury induced by mechanical ventilation in an isolated perfused rabbit lung model. Crit Care Med 1999, 27:1533-1541.

36. Moriondo A, Pelosi P, Passi A, Viola M, Marcozzi C, Severgnini P, Ottani V, Quaranta M, Negrini D: Proteoglycan fragmentation and respiratory mechanics in mechanically ventilated healthy rats. J Appl Physiol 2007 103:747-756

37. Chu EK, Whitehead T, Slutsky AS: Effects of cyclic opening and closing at low- and high-volume ventilation on bronchoalveolar lavage cytokines. Crit Care Med 2004, 32:168-174.

38. Sinclair SE, Chi E, Lin HI, Altemeier WA: Positive end-expiratory pressure alters the severity and spatial heterogeneity of ventilator-induced lung injury: an argument for cyclical airway collapse. J Crit Care 2009, 24:206-211.

39. De Smet HR, Bersten AD, Barr HA, Doyle IR: Hypercapnic acidosis modulates inflammation, lung mechanics, and edema in the isolated perfused lung. J Crit Care 2007, 22:305-313.

40. Broccard AF, Hotchkiss JR, Vannay C, Markert M, Sauty A, Feihl F, Schaller MD: Protective effects of hypercapnic acidosis on ventilatorinduced lung injury. Am J Respir Crit Care Med 2001, 164:802-806.

41. Peltekova V, Engelberts D, Otulakowski G, Uematsu S, Post M, Kavanagh BP: Hypercapnic acidosis in ventilator-induced lung injury. Intensive Care Med 2010, 36:869-878.

doi:10.1186/cc10502

Cite this article as: Xia et al:: Effect of spontaneous breathing on ventilator-induced lung injury in mechanically ventilated healthy rabbits: a randomized, controlled, experimental study. Critical Care 2011 $15 \cdot R 244$

\section{Submit your next manuscript to BioMed Central and take full advantage of:}

- Convenient online submission

- Thorough peer review

- No space constraints or color figure charges

- Immediate publication on acceptance

- Inclusion in PubMed, CAS, Scopus and Google Scholar

- Research which is freely available for redistribution 